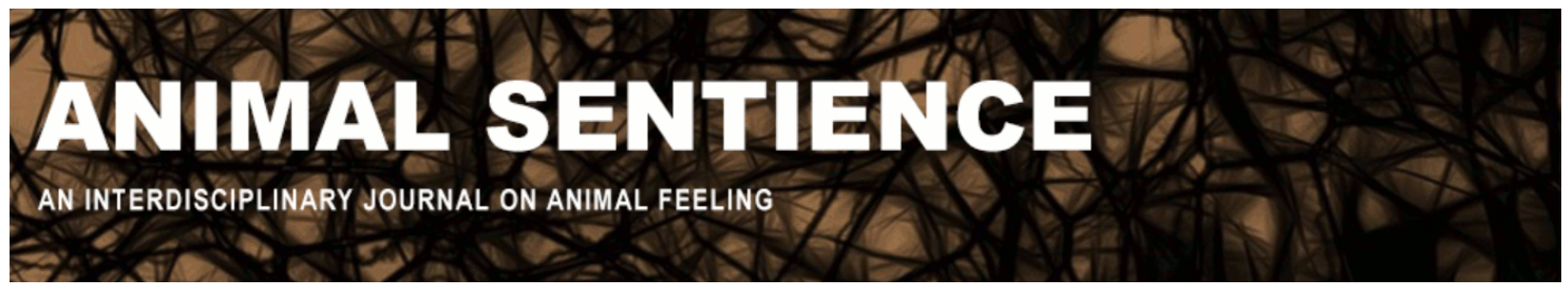

Jensvold, Mary Lee (2018) Lessons from chimpanzee sign language studies. Animal Sentience 20(17)

DOI: $10.51291 / 2377-7478.1306$

Date of submission: 2018-02-05

Date of acceptance: 2018-02-13

(c)

This article has appeared in the journal Animal

Sentience, a peer-reviewed journal on animal

cognition and feeling. It has been made open access,

free for all, by WellBeing International and deposited

in the WBI Studies Repository. For more information,

please contact

wbisr-info@wellbeingintl.org.

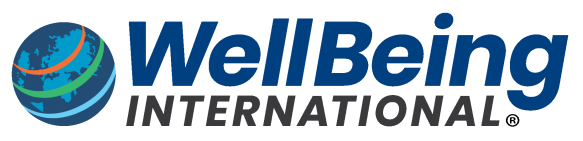

SOLUTIONS FOR PEOPLE, ANIMALS AND ENVIRONMENT 


\title{
Lessons from chimpanzee sign language studies
}

Commentary on Peña-Guzmán on Animal Suicide

\author{
Mary Lee Jensvold \\ Primate Behavior \\ Central Washington University
}

\begin{abstract}
Claims are often made about behaviors being unique to humans; the evidence usually shows they are not. Sign language studies on chimpanzees may provide a useful model for comparative studies of suicide. A productive approach to comparative studies is to focus on observable behaviors rather than getting lost in the pitfalls of vague definitions and changing measures.
\end{abstract}

Mary Lee Jensvold, Senior Lecturer, Primate Behavior Program, Central Washington University, and Associate Director, Fauna Foundation, specializes in ethological studies of apes, animal intelligence, communication, language, culture, and advocacy in captive care. www.friendsofwashoe.org/meet/drmary-lee-jensvold.html

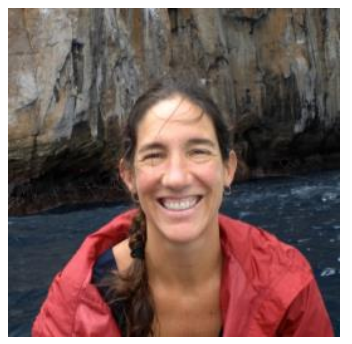

Peña-Guzmán's (2017) target article makes a philosophical argument against the claim that suicide is unique to humans. Claims have been made for centuries about behaviors supposedly unique to humans; they have usually failed to pass the test of evidence. In 1968, Goodall observed chimpanzees making and using tools, a behavior that had been thought to occur only in humans. We now know that chimpanzees and other nonhuman animals such as corvids are prolific tool users (Clayton \& Emery, 2005). Similar claims have been made about culture, language, and intention; again, evidence has shown otherwise. The way sign language has been studied in chimpanzees may provide a useful model for how to go about the comparative study of suicide.

At the outset, the phenomena of interest may be defined vaguely, narrowly, or broadly, or researchers may not agree on a definition at all. Language has been defined as something reserved for the vocal modality (Hockett, 1959), or bee communication has been taken to be a language (von Frisch, 2014). Some definitions of culture are narrow, applying only to humans; others are broad and allow cross-species comparisons (Boesch, 2003; Leland \& Hoppit, 2003). Arguments about definitions can prevent new discoveries from being made.

When nonhumans exhibit the same behaviors as humans, some researchers label it differently, as Peña-Guzmán points out. The behaviors called "cultural' in humans become "protocultural" in non-humans (Washburn, 1959). What is called language in humans becomes "protolanguage" or "ape language" (Savage-Rumbaugh, 1986) in other species. The labels for behaviors in mental illness are an interesting example. 
Many behaviors recognized and treated as abnormal in humans have been observed in nonhumans: pacing, jerking, phantom limb, self-biting, hitting, poking, eating feces, to name a few (Birkett \& Newton-Fisher, 2011). Yet these same abnormal behaviors were at first not recognized as indicators of pathology in nonhumans. Then in the 50s and 60s, researchers deliberately induced abnormal behavior in monkeys and chimpanzees. The famous deprivation experiments (e.g., Harlow, 1958; Berkson, Mason, \& Saxon, 1963; see Gilmer \& McKinney, 2003, for review) were designed to create nonhuman models of mental illness.

In 1986, the United States Animal Welfare Act required that we provide for the psychological well-being of nonhuman primates. This led to discussion about what constitutes psychological well-being, along with a resurgence in research on mental health in nonhumans, particularly stereotypic and self-injurious behaviors. The motivation for the research at that point was compliance with federal laws. Yet it is only in the last ten years that researchers are venturing to use labels like anxiety, compulsive disorders (Ferdowsian et al., 2012), and post-traumatic stress disorder (Bradshaw et al., 2008) with nonhuman species. This is a positive step in accepting continuities between species.

Certain behaviors and traits are simply assumed to be all-or-none. Peña-Guzmán points this out in the case of reflexivity. The same assumption has been made about language. But consider the appearance of language in a human infant. Children do not wake up one morning finding themselves able to speak in complete sentences with a sizable vocabulary. Both first- and second-language learning is gradual and continuous rather than all-or-none:

"Truly discontinuous, all-or-none phenomena must be rare in nature. Historically, the great discontinuities have turned out to be conceptual barriers rather than natural phenomena. They have been passed by and abandoned rather than broken through in the course of scientific progress." (Gardner, Gardner, \& Van Cantfort, 1989, p. xvii)

A productive approach to comparative studies is to focus on observable behaviors rather than apriori definitions. The successes of sign language studies with cross-fostered chimpanzees came from treating them under comparable conditions and using the same measures of language acquisition in infant chimpanzees as the ones used in human children (Gardner \& Gardner, 1978; Gardner, Scheel, \& Shaw, 2011). The data compared included the first 50 signs, vocabulary size and production, and the recombination and modulation of signs (Rimpau, Gardner, \& Gardner, 1989). To test conversational competence in chimpanzees, later researchers used human conversational competence measures such as responses to WH-questions (Gardner, Van Cantfort, \& Gardner, 1992), responses to misunderstanding (Jensvold \& Gardner, 2000; Leitten, Jensvold, Fouts, \& Wallin, 2012), initiation of conversations (Bodamer \& Gardner, 2002), and topic maintenance (Chalcraft \& Gardner, 2005).

Similar methods can be applied to suicide. What behaviors constitute suicide? Which of these behaviors appear in humans? Which of them appear in nonhumans? Through clear operational definitions of behaviors and an understanding of Darwinian principles, we can come to understand what constitutes suicide and how it is manifested. 


\section{References}

Berkson, G., Mason, W. A., \& Saxon, S. V. (1963). Situation and stimulus effects on stereotyped behaviors of chimpanzees. Journal of Comparative and Physiological Psychology, 56(4), 786.

Birkett, L. P., \& Newton-Fisher, N. E. (2011). How abnormal is the behaviour of captive, zooliving chimpanzees?. PloS One, 6(6), e20101.

Bodamar, M. D., \& Gardner, R. A. (2002). How cross-fostered chimpanzees (Pan troglodytes) initiate and maintain conversations. Journal of Comparative Psychology, 116(1), 12.

Boesch, C. (2003). Is culture a golden barrier between human and chimpanzee? Evolutionary Anthropology, 12, 82-91. doi: 10.1002/evan.10106

Bradshaw, G. A., Capaldo, T., Lindner, L., \& Grow, G. (2008). Building an inner sanctuary: complex PTSD in chimpanzees. Journal of Trauma \& Dissociation, 9(1), 9-34.

Chalcraft, V., \& Gardner, R. A. (2005). Cross-fostered chimpanzees modulate signs of American Sign Language. Gesture, 5, 107-132.

Clayton, N., \& Emery, N. (2005). Corvid cognition. Current Biology, 15(3), R80-R81.

Ferdowsian, H. R., Durham, D. L., Johnson, C. M., Brüne, M., Kimwele, C., Kranendonk, G., Otali, E., Akugizibweg, T., Mulcahyh, J. B., \& Ajarova, L. (2012). Signs of generalized anxiety and compulsive disorders in chimpanzees. Journal of Veterinary Behavior: Clinical Applications and Research, 7(6), 353-361.

Gardner, R. A., \& Gardner, B. T. (1978). Comparative psychology and language acquisition. Annals of the New York Academy of Sciences, 309, 37-76.

Gardner, R. A., Gardner, B. T., \& Van Cantfort, T. E. (Eds.). (1989). Teaching sign language to chimpanzees. Suny Press.

Gardner, R. A., Scheel, M. H., \& Shaw, H. L. (2011). Pygmalion in the laboratory. The American Journal of Psychology, 124(4), 455-461.

Gardner, R. A., Van Cantfort, T. E., \& Gardner, B. T. (1992). Categorical replies to categorical questions by cross-fostered chimpanzees. The American Journal of Psychology, 27-57.

Gilmer, W. S., \& McKinney, W. T. (2003). Early experience and depressive disorders: human and non-human primate studies. Journal of Affective Disorders, 75(2), 97-113.

Harlow, H. F. (1958). The nature of love. American Psychologist, 13(12), 673.

Hockett, C. F. (1959). Animal "languages" and human language. Human Biology, 31(1), 32-39.

Jensvold, M. L. A., \& Gardner, R. A. (2000). Interactive use of sign language by cross-fostered chimpanzees (Pan troglodytes). Journal of Comparative Psychology, 114(4), 335.

Leitten, L., Jensvold, M. L. A., Fouts, R. S., \& Wallin, J. M. (2012). Contingency in requests of signing chimpanzees (Pan troglodytes). Interaction Studies, 13(2), 147-164.

Leland, K., \& Hoppitt, W. (2003). Do animals have culture? Evolutionary Anthropology, 12, 150 159.

Lopresti-Goodman, S. M., Kameka, M., \& Dube, A. (2012). Stereotypical behaviors in chimpanzees rescued from the African bushmeat and pet trade. Behavioral Sciences, 3(1), 120.

Peña-Guzmán, D. M. (2017). Can nonhuman animals commit suicide? Animal Sentience 20(1).

Rimpau, J. B., Gardner, R. A., \& Gardner, B. T. (1989). Expression of person, place, and instrument in ASL utterances of children and chimpanzees. In Teaching sign language to chimpanzees, 240-268. 
Savage-Rumbaugh, E. S. (1986). Ape language: From conditioned response to symbol. Columbia University Press.

Van Lawick-Goodall, J. (1968). The behaviour of free-living chimpanzees in the Gombe Stream Reserve. Animal Behaviour Monographs, 1, 161-IN12.

Von Frisch, K. (2014). Bees: Their vision, chemical senses, and language. Cornell University Press. Washburn, S. L. (1959). Speculations on the interrelations of the history of tools and biological evolution. Human Biology, 31(1), 21-31. 